masse by blunt dissection. Figure 3 represents the operation completed.

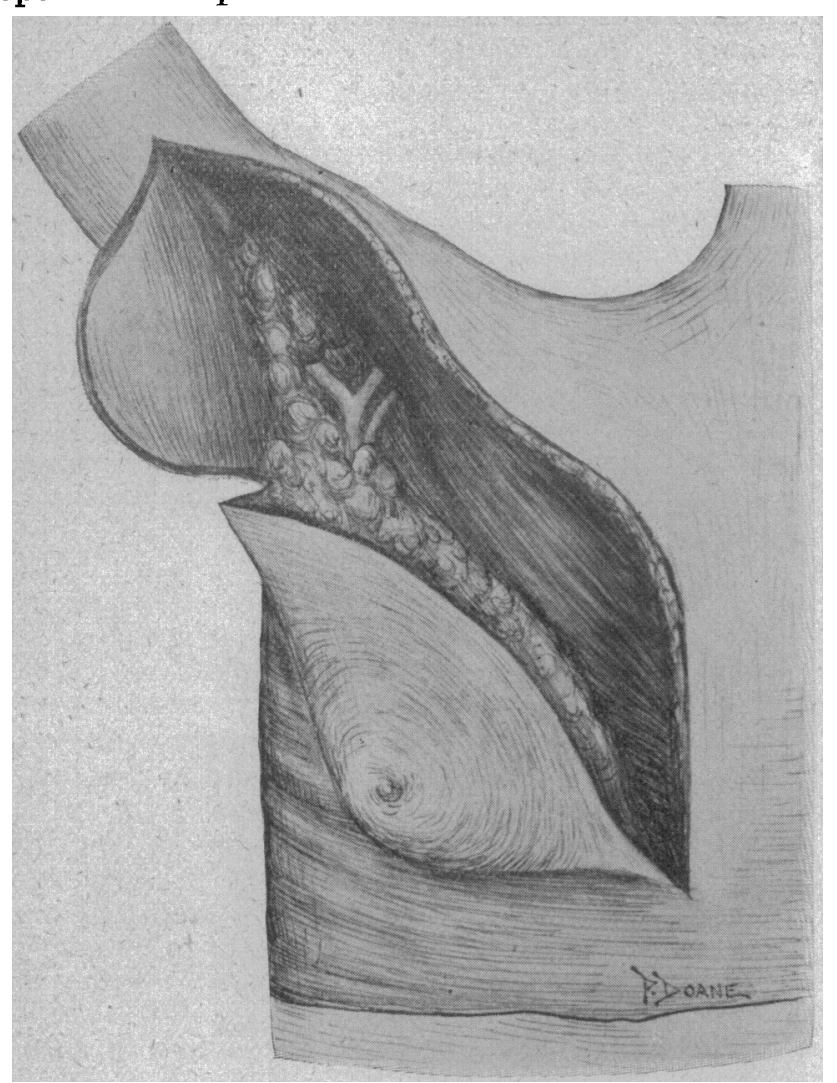

I wish to lay stress on the following advantages of the anterior axillary incision:

1. It exposes to the operator a larger field for radical work than the ordinary axillary incision.

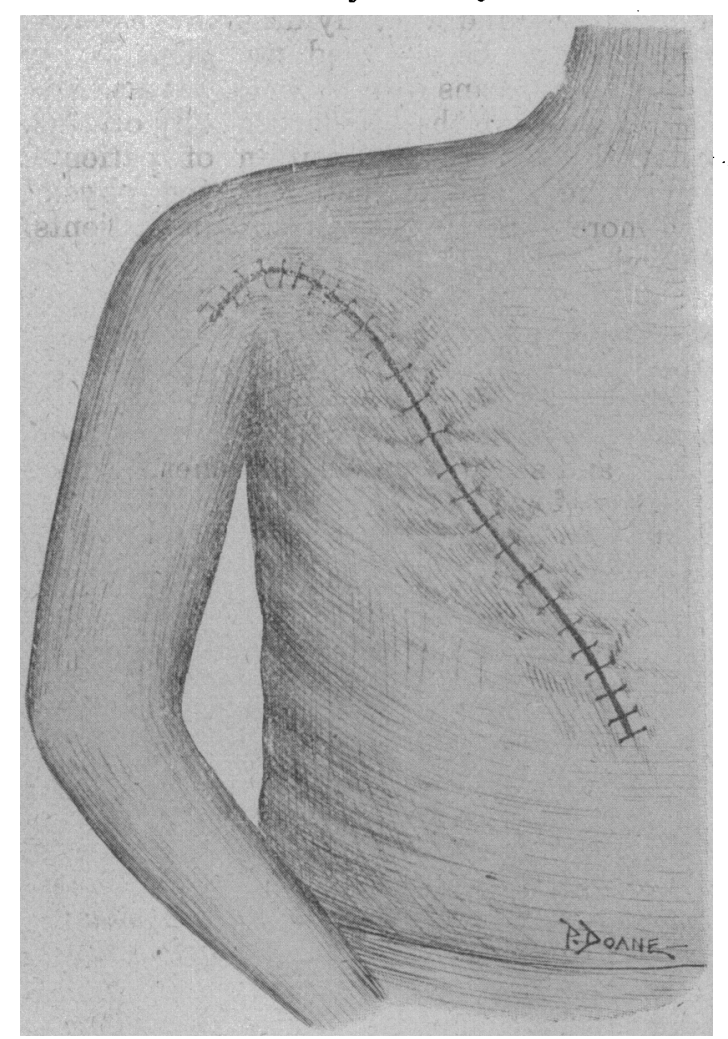

2. By making traction on the axillary flap, it is easily freed from the subcutaneous tissues with a few strokes of the knife, exposing at once the position of the axillary vein.

3 . Injury to the vein is greatly diminished, because the incision bares all the surrounding muscular landmarks to this important structure. Moreover dissection is done away from the vein instead of toward the vein, as must be done through an incision in the axilla.

4. The axillary space is unfavorable to primary wound healing, being often the seat of a fistula long after the rest of the wound has healed intact. It is a region difficult to render aseptic; hence the advantage of access to this region from without.

5. The incision is so situated that it does not im. pede free motion of the arm, the patient being able to extend the arm to the head at the first dressing. There is no subsequent cicatricial contraction, as in an axillary scar, to interfere with the physiologic function of the arm.

6 . The cicatrix is not dragged upon by motion of the arm, consequently scar tissue is little exposed to trauma through mechanic stretching; hence the diminished liability of recurrence of the disease.

\section{THE MEDICAL WITNESS.*}

HIS RIGHTS AND WRONGS IN COURTS OF JUSTICE.

\section{BY JAMES B. BAIRD, M.D.} ATLANTA, GA.

Unquestionably the medical witness has some rights, and as surely does he suffer many wrongs. The rights, briefly stated, refer to the proper treatment of the physician on the witness stand; to a just recugnition of the relationship existing, or which ought to exist, between the physician and his patient; and to a true valuation of his expert services. The wrongs, in a word, relate to a misconception of bis rights, br to an utter disregard of them.

The treatment accorded the physician on the stand depends, in great measure upon the witness himself, and in part upon the court and the attorneys engaged in a given case. But few lawyers-none of the better class - will undertake to mistreat a medical witness who demeans himself with propriety, who actually possesses the information which he claims, or ought to have, and who gives his evidence or states his opinion in a simple, straightforward manner, without seek. ing to magnify himself, to dazzle his hearers by a display of profound erudition, or by the assumption of a degree of knowledge which he does not possess. But few judges will permit a competent and sincere witness to be badgered, bullied or ridiculed, even if such tactics should be attempted by a discourteous attorney.

If the principal object of all legal proceedings in court were simply to ascertain and to establish the truth, the task set before the expert witness would be greatly simplified. There would then be no incentive to confuse, to mislead or to combat the witness. But, unfortunately, such a purpose is not usually a predominant influence. Each side is intent on sustaining its own contention, and each seeks testimony tending to strengthen the position of the advocate. Hence, questions are adroitly framed, and answers are often ingeniously warped or distorted with the design of eithef impressing or suppressing certain salient points, 
and the comfort of the witness is not considered of paramount importance in the management of the game.

Nevertheless, the mere treatment of the medical witness in the ordinary prosecution of a case in open court is chiefly of personal interest, that is, it relates to the individual rather than to the profession-for he may, if he can, use the legitimate, the recognized, and the generally successtul means of self.defense against imposition. The most trustworthy weapons at his command are ability, evident honesty of purpose, quickness of perception, self-control, and that wonderfully serviceable quality which we call tact. $\mathrm{H}_{\theta}$ may greatly strengthen and effectually shield himself by declining all show of partisanship, by avoiding all manifestation of prejudice and by studiously abstaining from the use of strictly technic terms; by a candid, unbiased statement of facts, and by a clear, definite expression of well-founded opinion in plain, lucid language, but always refraining from obstinate adherence to mere dogmatic assertion, and from the attempt to explain what is not understood, to tell what is not known or to maintain an opinion which is not fixed and which is not firmly believed.

In theory, the relation between the physician and his patient is confidential. In theory, the knowledge and the skill of the physician constitute his capital. In practice and in common law, communications to the physician by his patient are not confidential, and the knowledge of the physician may be exacted of him at uny personal cost or sacrifice, without fee or reward, by or through the arbitrary processes of the courts.

These are facts. Are they real evils? Are they genuine wrongs? If so, is there a remedy? Where can it be found, and how may it be applied?

In reference to the first proposition, which is the more important of the two, the "American and English Encyclopædia of Law" says, in substance: At common law, confidential communications made by a patient to a physician are not privileged, but by statutes in several States communications made by a patient to his physician or surgeon, and information acquired by him while attending a patient in a professional capacity, and which are important to ensble him so to act, are protected. The States in which such statutes have been enacted are: Arkansas, California, Colorado, Dakota, Idaho, Indiana, Iowa, Kansas, Michigan, Minnesota, Missouri, Montana, Nevada, New York, Ohio, Oregon, Utah, Washington, Wisconsin and Wyoming. In the States named the privilege extends to facts necessary to enable the physician to prescribe, and which are communicated to him for the purpose of enabling him to perform his professional duties. Such facts are privileged, whether learned directly from the patient himself or acquired by the physician through his own observation or examination; further, it does not extend. The privilege is not necessarily terminated by death. Whether the statutes protecting confidential communications between physician and patient extend to criminal cases is not well settled. The provision in the California code, for instance, is expressly limited to civil actions, while in New York the decisions seem to hold that the statute applies also to criminal cases.

Clergymen and priests, like physicians, are, at common law, unprotected in communications and confessions made to them. By statute in some of the States they are shielded to a limited degree in the exercise of their peculiar functions. Current public opinion, however, generally sustains the privilege voiced by these special statutes, even in States where they do not exist, and, from considerations of policy and expediency, the spiritual advisers of the people are seldom required to disclose confidences in courts of justice.

The object of statutes relating to privileged communications to physicians seems to be to place the communications made to physicians in the course of their professional employment on the same footing with communications made by clients to their attorneys in the course of their employment.

The character of the communication as to being important or material is of no consequence, and to entitle a client to this protection it is not essential that he should be apprised of the rule, or that he should enjoin secrecy. The privilege is that of the client, and not of the attorney.

At common law, as well as under statutes, the protection given privileged communications continues forever, unless waived by the client, and such waiver must be distinct and unconditional, and can not be extinguished by agreement or compromise. Communications to attorneys that do not $\operatorname{com} \theta$ within the peculiar scope of the lawyer's duty and profession, or that have no elements of confidence in them, or that are made for any unlawful purpose, having for their object the commission of a crime, are not privileged.

The fact that twenty States of this Republic have by special statutory enactment sought to remedy an omission or defect in the common law, and to place thereby physicians in the same category with attorneys, is equivalent to an admission of an existing evil; it is a tacit acknowledgment of a positive wrong and a practical suggestion of an efficient remedy. The personal experience of some physicians and of some law. yers in this State conclusively confirms the reasonable inference drawn from the deliberate action of these twenty States, and liberally discounts a rule of action which ought to be changed, not alone in justice to the 2600 physicians of this State, but also and chiefly in the interest of that far larger body of citizens who occupy the dependent position of patients. Such statutes mean simple justice to the physician, but much more than mere justice to his patients. They are serviceable to the physician only in so far as they enable him to be faithful to his professional obligations and true to his trusts, and in such degree alone as they protect him from acting the part of an involuntary and reluctant detective, informer or spy, all of which is obnoxious to his instincts, abhorrent to his feelings and at variance with the cherished tenets and traditions of his honored profession.

But to the large number of persons-to the great bulk of the people-who are from force of circumstances compelled to confide in the discretion and honor as well as in the wisdom and skill of their medical adviser, such laws are of most profound import and of far-reaching consequence. In their behalf, then, being cognizant of the conditions, it behooves the medical men of the State, unselfish and patriotic, to move for a remedy.

From satisfactory evidence, I conclude that the trend of public opinion is decidedly in favor of protecting the professional secrets of physicians. Why not, therefore, crystallize this public sentiment in the form of a statute, and thereby give to the preference of the people the force and effect of written law? The second proposition is one in which the medical 
profession is more directly concerned than the general public, but it affects the interests of both. In the State of Georgia, the right to employ experts to elucidate questions before the court is fully recognized and freely accorded by express statute, which, in terms, declares that expert testimony on any question of science, skill, trade or like subject is admissible. An expert is defined as one who has made the subject on which he gives his opinion a matter of particular study, practice or observation. He must have a par. ticular and special knowledge on the subject, and such opinions may be given also, on facis as proved by other witnesses. Ample provision is made for obtaining expert services through the machinery of the court, but no provision whatever is made for adequate compensation to those who, under a heavy penalty for failure, are required to lay aside all other business and to attend the sessions of the court until excused therefrom.

To secure the attendance of a witness in the county of his residence for the benefit of his opinion, in criminal prosecution, as in the case of a witness to the facts, it is only necessary for the clerk of a superior court to issue, on application, a subpena commanding bim to appear at a stated time. No restriction is placed on either side in summoning witnesses within the county. For his detention he is allowed a per diem of 75 cents, but this munificent allowance must come out of a fund accumulated from fines and forfeitures, which is always exhausted by prior liens, so that even this show of generosity goes for naught.

In civil cases, a medical witness can not be carried out of his county against his will, and his testimony is obtained through the medium of interrogatories, and even in civil causes pending in the county of his residence obedience to summons is discretionary with the practicing physician, but he may be forced to answer interrogatories in any civil case, either within or without the county.

In criminal cases, his attendance may be required in any county within the State. But in this event, the subpena, issued as in the home county, by the clerk of the superior court, must be countersigned by the solicitor-general of the circuit. For attendance on court in another county, all witnesses for the State are alike allowed $\$ 2$ a day and mileage not to exceed four cents a mile necessarily traveled in obeying the summons.

Witnesses on behalf of the defendant in criminal cases can only be compelled to attend court in another county when so directed by the presiding judge, who may, in his discretion, so order when, in his opinion, the ends of justice demand it, and under these circumstances, the defendant's witnesses are entitled to receive the same remuneration from the county as the State's witnesses. Otherwise, they are voluntary witnesses, and are not given a per diem or traveling expenses out of the public funds. They have, however, a lawful claim on the defendant for compensation not to exceed the amount allowed witnesses who are duly summoned. But the claim, in the great majority of cases, is worthless, as such defendants are usually insolvent. The duty of the citizen to aid in the administration of the government whenever his services are required is readily conceded, and the special consideration manifested toward the medical profession on the part of the State, by relieving its members from certain public functions, as ordinary jury duty, imperative obedience to summons in civil causes, etc., in deference to the physician's relations to sosi. ety, is duly appreciated, but the obligation of citizenship should be equally distributed and should not be heavily imposed upon the few.

In the nature of the case, the services herein referred to must be rendered by a comparatively limited number, and the only way to equalize the burden is to return a just compensation, out of the common fund of the people, for the professional and scientific knowledge contributed by the few in behalf of the many.

If a party to a suit should avail bimself of his lawful privilege, and employ, as is usually done in important cases, competent expert services, the fact that a fee is paid the expert is often used by opposing counsel to discredit the witness with the jury by making it appear that self-interest influences his evidence, and, either by assertion or by innuendo, suggesting that his opinion is controlled or directed by pecuniary consideration.

Several States have etatutes providing a reasonable remuneration for expert services; among the number are Iowa, Now York, North Carolina and Rhode Island, and, so far as I am informed, their operation is satisfactory. In one State at least, Indiana, it has been provided by statute that experts shall testify without extra compensation.

In a case before the United States Court in the District of Massachusetts, the court said: "When a person has knowledge of any fact pertinent to the issue to be tried, he may be compelled to attend as a witness. In this all stand upon an equal ground But to compel a person to attend merely because he is accomplished in a particular science, art, or profession, would subject the same individal to be called upon in every cause in which any question in his department of knowledge is to be solved. Thus, the most eminent physician might be compelled, merely for the ordinary witness fees, to attend from the remotest part of the district, and give his opinion in every trial in which a medical question should arise. This is so unreasonable that nothing but necessity can justify it."

Before the adoption of the prohibitory statute by Indiana, the supreme court of that State held that: "When a physician testifies as an expert, by giving his opinion, he is performing a strictly professional service. The purpose of his service is not to prove facts in the cause, but to aid the court or jury in arriving at a proper conclusion from facts otherwise proved." It also held that such witnesses were entitled to just compensation for the particular service. The United States Court for the Western District of Arkansas ruled that when a witness has facts within his knowledge the public has a right to those facts, but the skill and professional experience of a man are his individual capital and property and he can not justly be compelled to bestow them upon any one as a gratuity; that neither the public nor a private person can rightly extort such services without proper remuneration.

Contrary opinions have been rendered in Alabama, in Texas, and perhaps in other States. In English courts it has been held that it is more correct to regard professional and scientific knowledge in the light of property which the public has no right to use without making proper compensation.

It seems to me that no argument beyond the bare statement of the facts is necessary to sustain the view that the medical profession and the people suffer in 
consequence of our inadequate laws upon these points. If the laws of the State are truly inadequate or defective, such inefficiency and defect must constitute an evil; and if the citizen, in consequence of such imperfection, does suffer, there must be a wrong; so, if the evil and the wrong really exist, as is confidently believed, appropriate legislation judicially applied is the only and the proper remedy. Legislation which makes confidential communications to the physician privileged communications, and which provides, in the discretion of the court, just compensation for expert medical services, will correct the evil and right the wrong, and toward the procurement of such legislation in the interests of the meaical profession and of the people of this commonwealth, the united efforts of this association should be diligently addressed.

\section{REPORT ON MASSAGE.}

MASSAGE FOR MOVABLE KIDNEY-IN GOUT-IN FRIED. REICH'S DISEASE-IN LOCOMOTOR ATAXIA-FOR DISPLACED SEMILUNAR CARTILAGESIN SKIN DISEASES AND ULCERS. PAPER NO. III.

BY DOUGLAS GRAHAM, M.D. BOSTON, MASS.

(Continued from page 412.)

MASSAGE FOR MOVABLE KIDNEY.

Fellner speaks highly of the good effects of abdominal and pelvic massage for the cure of movable kidney. Of 98 cases of this affection he used this treat. ment in 40 severe ones, and found that the disagreeable feelings were removed and the kidney resumed its natural position in all but two patients. In 11 cases, 5 of which are minutely detailed, the good effects were observed a year or two after. Of the 98 cases, all were women. The affection occurred 67 times in the right side, 15 in the left, 19 double. Sixty-seven had given birth to children, and of these, 48 were multiparæ. In 53 cases there were also pelvic troubles. An acute injury seemed to be the starting-point in 5. There were digestive disturbances in 38 , and disturbances of the intestinal functions in 59. In many there was frequent urgency to urinate; in two cases there was intermittent albuminuria, and in two hydronephrosis.

The author points out that it is not right to call every movement of the kidney, upon breathing, movable kidney, because every kidney has physiologic movements. Naturally, it is only when decidedly out of place and causing disturbance that attention should be directed to it, and from an examination of 2900 cases for movable kidney, he certainly has the right to speak authoritatively. With kidneys unduly movable, neurasthenic symptoms were often present-palpitation of the heart, anxiety, difficulty of breathing, feelings of oppression, nervous cough, globus, dizziness and fainting, and sometimes melancholia. In all the cases treated by massage the patients were relieved of their discomforts during this treatment, and the objective results were also evident. ${ }^{1}$ MASSAGE IN GOUT.

Our learned friends in France tell us that in chronic gout the good effects of massage are generally recog. nized, but opinions differ as to the best time to use it. M. Lecorché, M. Bouchard and M. Gendre recommend massage after the acute stage, in order to combat muscular atropy, to favor the absorption of infiltrations, to

\footnotetext{
1 Wiener Med. Woch., No. x, 1896, p. 398.
}

break up the tophaceous concretions, and to oppose fibrous ankylosis. During an acute attack it is well to abstain from using massage. M. Rosenblith, however, claims to have obtained good results from its use in seven cases of acute gout, but his opinion is not shared by his confrères."

The London Lancet (Oct. 2, 1897) sounded a note of warning on this subject, in pointing out that the gonty kidney is seldom or never quite equal to its functions. Here it thinks an unqualified and overenthusiastic masseur might do much harm as he goes ploughing away at muscles infiltrated with-uric acid, creating as much waste as a brisk six-mile walk and more than the kidney can throw off. Kept up from day to day, for weeks, this practice may be destructive to an already damaged kidney, and the patient may find that though he has got rid of a certain amount of pain and acquired a comparative ease of movement, yet this may be at the expense of renal incompetence and eventual uremia. On the Continent this is said to be of frequent occurrence, where massage is practiced with more zeal than knowledge.

"We have allowed the quacks to get ahead of us in the application of electricity to therapeusis," said Dr. Anstie, a long time ago. The same must with equal truth be said of massage, says the editor of the Lancet.

In gout and many other affections where massage and electricity are to be used, it would seem better that they should be applied by a physician rather than by the gymnastic masseur.

$$
\text { MASSAGE IN FRIEDREICH'S DISEASE. }
$$

Dr. Zabludowski of Berlin reports (Therap. Monatsh., December, 1896) a case of Friedreich's disease (hereditary ataxia), interesting on account of the youthful age of the patient-a girl of 9 years-and also because of the successful treatment of the case by massage. The patient was seen by Professor Mendel in consultation with Dr. Zabludowski, and the great improvement which a four-weeks course of massage effected was witnessed by both. The child then seldom fell, and could walk without deviation, and she did not let things fall out of her bands as formerly. The choreiform movements were scarcely visible and sleep was quiet.

$$
\text { MOVEMENTS IN LOCOMOTOR ATAXIA. }
$$

Dr. Frenkel of Heiden points out that the purpose and object of this treatment has been much misunder. stood. In tabes the muscles are perfectly contractile, and neither atrophic nor shortened, therefore it is often worse than useless to order gymnastic exercises. The nutrition of the muscle is not at fault, and it is not muscular contractions which are so much wanted as co-ordination - orderly and combined movements. ${ }^{1}$ The principle of the treatment in question is the exercise of the will in controlling and ordering the muscles to effect a given movement such as the seizing of a swinging ball. By the repetition of attempted efforts, the movements gain in precision and the ataxia is correspondingly overcome. The purposelessness of the gymnastic exercises as usually ordered is not only a mere contraindication by negation, but there is also involved a positive danger; for not infrequently the incitement to increased muscular exertion leads to exhaustion, and the danger of this is all the greater seeing that the patient is not possessed of the usual sense fatigue which guides us in health. In all

2 Révue d'Hygiene Thérap., 1896, p. 188. 1 The muscles are often reiaxed, elongated and thin; therefore
udicious contractions are indicated. 